\title{
DINAMISMOS ATUAIS DO CIRCUITO INFERIOR DA ECONOMIA URBANA NA CIDADE DE SÃO PAULO: EXPANSÃO E RENOVAÇÃO*
}

\author{
Marina Regitz Montenegro**
}

Resumo: A intensificação da participação do Brasil na divisão internacional do trabalho vem implicando a presença cada vez maior dos agentes da economia globalizada e de suas atividades modernas nas grandes metrópoles do país, sobretudo em São Paulo que se destaca no cenário internacional como uma das ditas cidades "globais". Não obstante, as metrópoles abrigam também uma enorme gama de atividades realizadas pela população pobre. Deste modo, contêm diferentes divisões do trabalho que coexistem e que, por sua vez, podem ser analisadas como circuitos da economia urbana (SANTOS, 1978). A partir da seleção de determinadas áreas da cidade de São Paulo que aparecem como verdadeiros "focos de concentração" do circuito inferior, procuramos compreender como se caracteriza este circuito hoje e, também, como este se relaciona com as variáveis centrais do período atual, entendidas aqui como a técnica, a informação, o consumo, a publicidade e as finanças.

Palavras-chave: circuito inferior, mercado de trabalho, globalização, pobreza, meio construído

\section{ACTUAL DYNAMICS OF THE LOWER CIRCUIT IN THE CITY OF SÃO PAULO: EXPANSION AND RENOVATION}

Abstract: The considerable increase of the brazilian participation in the international division of labor implies the growing presence of the globalized economic actors and its modern activities in the metropolis of the country, especially in São Paulo which stands out in the international scene as one of the so called "global" cities. However, these metropolis also host an enormous range of activities performed by the poor population. Hence, in these metropolis, different divisions of labor coexist and can be analyzed as circuits of the urban economy (SANTOS, 1978). From the selection of certain areas of the city of São Paulo that appear as "spots of concentration" of the lower circuit, we aim to understand the characteristics of this circuit today as well as how it relates to the key variables of the current period, or, the technique, information, consumption, advertisement and finance.

Keywords: lower circuit, labor market, globalization, poverty, environment building.

\section{Introdução}

No período atual, a intensificação da participação do Brasil na divisão internacional do trabalho vem implicando a presença cada vez maior dos agentes da economia globalizada e de suas atividades modernas nas grandes metrópoles do país, sobretudo em São Paulo que se destaca no cenário internacional como uma das ditas cidades "globais". No entanto, as metrópoles abrigam também uma enorme gama de atividades realizadas pela população pobre. Desse modo, elas contêm diferentes divisões do trabalho em coexistência.

$$
\text { Conforme propôs Santos (1978), }
$$

estas divisões do trabalho podem ser analisadas como circuitos da economia urbana. Segundo este autor (SANTOS, 1978,

\footnotetext{
* Neste artigo, apresentamos os principais resultados de nossa dissertação de mestrado, intitulada $O$ circuito inferior da economia urbana na cidade de São Paulo no período da globalização, realizada sob orientação da Prof $^{a}$ Dr $^{a}$ María Laura Silveira, pelo Programa de Pós-Graduação em Geografia Humana da Universidade de São Paulo (USP), e defendida em 2006.

** Doutoranda em Geografia Humana pela Faculdade de Filosofia, Letras e Ciências Humanas da Universidade de São Paulo - FFLCH-USP. E-mail: montenegromarina@hotmail.com
} 
p. 29), a economia urbana dos países subdesenvolvidos pode ser interpretada a partir da coexistência de dois circuitos de produção, de distribuição e consumo nas cidades desses países. As atividades urbanas e a população a elas associadas são distinguidas em função dos diversos graus de tecnologia, capital e organização que utilizam. Quando estes são altos, trata-se do circuito superior, incluindo sua porção marginal; quando são baixos, trata-se do circuito inferior.

O circuito superior - composto pelos bancos, comércio e indústria de exportação, indústria moderna, serviços modernos, atacadistas e transportadores - é o resultado direto das modernizações que atingem o território. Graças à importância crescente da informação e das finanças, os principais representantes do circuito superior são hoje as corporações globais, as empresas produtoras de informação e de serviços de alta tecnologia e os atores do sistema financeiro. Já o circuito superior marginal compreende uma porção do circuito superior que engloba tanto atividades "residuais" aquelas incapazes de acompanhar o ritmo de modernização da época - quanto atividades "emergentes", ligadas à natureza técnico-científica do trabalho contemporâneo, à profusão das normas, à relevância crescente do trabalho intelectual e à expansão dos consumos (SILVEIRA, 2007, p. 152).

O circuito inferior, por sua vez, compreende 0 resultado indireto da modernização e constituí-se de formas de fabricação não capital intensivo, serviços não modernos fornecidos a varejo, comércio não moderno e de pequena dimensão, voltados sobretudo ao consumo dos mais pobres. Enquanto a divisão territorial do circuito superior da economia envolve uma topologia de pontos nas cidades, no território nacional e no exterior; a divisão territorial do trabalho do circuito inferior sustenta-se fundamentalmente na cooperação e na contiguidade do bairro, da cidade ou da região, ainda que seus nexos tendam a se expandir no período atual. Vale relembrar que os circuitos não constituem sistemas fechados, estão, em realidade, interligados por intensas relações de complementaridade, concorrência e subordinação (SANTOS, 1978). Compreendem, assim, subsistemas do sistema urbano, no qual todas as formas de trabalho estão integradas (SILVEIRA, 2004b, p. 14).

A partir da seleção de determinadas áreas da cidade de São Paulo que aparecem como verdadeiros "focos de concentração" do circuito inferior - no Largo Treze de Maio e nos distritos centrais Sé, República, Santa Cecília e Bom Retiro - procuramos compreender como se caracteriza este circuito hoje e, também, como este se relaciona com as variáveis centrais do período atual, entendidas aqui como a técnica, a informação, o consumo, a publicidade e as finanças (MONTENEGRO, 2006). Orientados pela preocupação de ver a cidade como uma totalidade interconectada por diversas divisões do trabalho, em diferentes pedaços do meio construído, buscamos entender como o território constitui um abrigo para os atores não hegemônicos, na medida em que comporta atividades tão distintas e distantes em termos de graus de organização e de capital.

Neste sentido, partimos inicialmente da análise de dois processos inter-relacionados que caracterizam o território brasileiro hoje. Ao mesmo passo em que a modernidade - fundada num sistema técnico-informacional e num contexto neoliberal - 
vem se difundido pelo país ao longo das últimas décadas, a produção de pobreza estrutural amplia-se no território. Por um lado, atividades atreladas à modernidade do período se fazem cada vez mais presentes no país; no entanto, por seu arcabouço técnico e político forâneo, tendem a requerer cada vez menos um trabalho nacional. Por outro lado, tem-se o avanço da flexibilização e o forte aumento do desemprego. Multiplicam-se no território, por conseguinte, as formas de trabalho realizadas com capitais reduzidos, dependentes dos próprios conteúdos dos lugares onde estão inseridas.

Em São Paulo, a combinação desses elementos de ordem técnica e política vem implicando um processo de transformação e renovação de uma divisão do trabalho endógena à cidade, na medida em que o circuito inferior aumenta sua capacidade de abrigar cada vez mais pessoas e diversifica suas formas de manifestação.

Através da análise de certas situações geográficas consideradas reveladoras nas áreas selecionadas na cidade de São Paulo, buscamos apreender elementos significativos para desvendar as dinâmicas que caracterizam o circuito inferior no período atual, buscando revelar sempre a vinculação do local ao global, através da mediação da formação socioespacial brasileira. Enquanto uma combinação que envolve, de um lado, "pedaços contíguos de sistemas de objetos e das ações emanadas de um trabalho comum e, de outro, vinculações materiais e organizacionais longínquas e mais ou menos alheias ao lugar" (SILVEIRA, 1999, p. 27), a situação geográfica configura um instrumento metodológico basilar na busca da compreensão dos dinamismos atuais da economia pobre.
O olhar sobre o circuito inferior na cidade de São Paulo nos pede assim uma reflexão sobre a forma como este circuito se relaciona com as variáveis do período da globalização, assim como sobre as possíveis transformações na composição das características que o definiam na década de 1970. Diante da emergência de novas variáveis chave, os circuitos certamente vêm encontrando formas renovadas de manifestação.

A intensa urbanização, a reorganização do Estado e da economia, a monetarização da economia e da sociedade que vão se completando, os agregados de ciência, técnica e informação à vida social e ao território, e a diversificação e aprofundamento dos consumos são dados novos do período, que alteram a natureza do espaço no qual os circuitos da economia urbana se desenvolvem (SILVEIRA, 2004b, p. 3).

Não obstante, ambos os circuitos vão encontrar seus canais de desenvolvimento, recriando a conjuntura e conformando-se a ela, posto que ambos são resultados das modernizações que atingem o território e a sociedade.

\section{Expansão e resistência do circuito inferior}

A partir da segunda metade dos anos 1980, o mercado de trabalho brasileiro passa, cada vez mais, a estar marcado pela forte redução do emprego assalariado formal, pelo aumento do número de vagas assalariadas sem registro e das ocupações não assalariadas, pelo recuo da proteção social e trabalhista, e pela precarização das condições e das relações de trabalho. E é justamente nas metrópoles - onde o contingente de 
pobres se multiplica mais rapidamente - que esses processos adversos do mercado de trabalho são sentidos com maior intensidade. É também nas metrópoles onde o circuito inferior tende a ampliar e diversificar suas formas de manifestação. Nos últimos anos, a pobreza no Brasil tem se tornado, com efeito, cada vez mais um fenômeno urbano e metropolitano. Enquanto a participação dos pobres rurais no total de pobres no país se reduziu de 24,3\% para 15,3\% entre 1992 e 2004; a participação metropolitana e urbana neste total cresceu significativamente no país, passando, respectivamente, de $31,2 \%$ a $36,3 \%$ e de $44,5 \%$ a $48,4 \%$, no mesmo período (ROCHA, 2006).

Desde a década de 1990, constata-se que a maior parte das ocupações nas metrópoles brasileiras vem sendo gerada em atividades ditas de baixa "produtividade", especialmente em micro e pequenas empresas, caracterizadas por uma baixa capitalização (CACCIAMALI; SILVA, 2003), em contraposição ao circuito superior, que vem se tornando cada vez mais poupador de mão de obra. Ainda que o conceito de circuito inferior não coincida com a definição de micro e pequena empresa, ${ }^{1}$ uma vez que o primeiro envolve todas as formas de trabalho que proporcionam renda e que sejam desenvolvidas com capital reduzido e com baixo grau de organização nas cidades, consideramos que os dados referentes às

\footnotetext{
1 Segundo a classificação adotada pelo Sebrae (2005), microempresas correspondem às empresas com até 19 pessoas ocupadas na indústria e com até 9 pessoas ocupadas no comércio e serviços; as pequenas empresas, por sua vez, correspondem às empresas que têm de 20 a 99 pessoas ocupadas na indústria e de 10 a 49 pessoas ocupadas no comércio e em serviços. Já segundo a metodologia empregada pelo IBGE no Cadastro Central de Empresas, as microempresas são aquelas que ocupam até 9 pessoas, as pequenas de 10 a 49 pessoas, as médias de 50 a 249 pessoas e as grandes mais de 250 pessoas, independentemente do setor de atividade (IBGE, 2006).
}

micro e pequenas empresas nos revelam processos que envolvem o circuito inferior no período atual.

Entre 1996 e 2002, o número de microempresas no Brasil evoluiu de 2.956.749 para 4.605.607, representando $93,6 \%$ do total de empresas do país em 2002. Conforme revela a Tabela 1, entre 1996 e 2002, o segmento das microempresas elevou sua participação no total de ocupados no país em empresas de $31,8 \%$ para $36,2 \%$. Embora tenha havido uma redução percentual em sua participação entre 2002 e 2006, os micronegócios, que ocupavam 6,9 milhões em 1996, passaram a ocupar cerca de 10 milhões de pessoas em 2006, totalizando um aumento de $45 \%$ em 10 anos (IBGE, 2002; 2006). Estas cifras nos revelam a dimensão do número de empregos criados, em termos absolutos, pelas microempresas nesse intervalo. Destacam-se, por outro lado, a intensidade da redução da capacidade empregatícia das grandes empresas no mesmo período e o fato de que as microempresas venham superando o número de ocupações oferecidas pelas maiores desde 2002. De acordo com Pochmann (2010, p. 63), mais de dois terços dos empregos formais gerados na última década no Brasil provêm de micro e pequenos negócios.

Tabela 1 - Distribuição percentual das pessoas ocupadas em empresas no Brasil por porte de empresa em 1996, 2002 e 2006 (\%)

\begin{tabular}{lccc}
\hline $\begin{array}{l}\text { Porte da } \\
\text { empresa }\end{array}$ & $\mathbf{1 9 9 6}$ & $\mathbf{2 0 0 2}$ & $\mathbf{2 0 0 6}$ \\
\hline Micro & 31,8 & 36,2 & 32,3 \\
\hline Pequena & 18,8 & 21,0 & 21,1 \\
\hline Media & 11,5 & 9,8 & 14,6 \\
\hline Grande & 37,9 & 33,0 & 32,0 \\
\hline Total & 100,0 & 100,0 & 100,0 \\
\hline
\end{tabular}

Fonte: IBGE (2002; 2006). 
A este quadro soma-se ainda a crescente participação das empresas consideradas "informais". Em 1997, estimava-se a existência de cerca de 9,5 milhões de empreendimentos informais nas áreas urbanas do país, que, por sua vez, ocupavam mais de 12 milhões de pessoas. Já em 2003, o número estimado de empresas do "setor informal" urbano passa para 10,3 milhões; e o total de pessoas ocupadas nas mesmas sobe para 13,8 milhões (IBGE, 2005).

Consideramos que esse forte aumento do número de micro e pequenas firmas de capital reduzido - mas não necessariamente não registradas - e das ocupações por elas oferecidas, assim como sua diversificação, estão fortemente ligados à expansão e à renovação do circuito inferior no período atual.

Vale ressaltar, por outro lado, que esse contexto de multiplicação das relações de emprego precárias vem revigorando enfoques como o da "economia informal" ou do "setor informal" (LAUTIER, 1994), que apresentam grande visibilidade desde a década de 1970. Apesar dos avanços na elaboração dos conceitos de informalidade e de "economia informal" (CACCIAMALI, 1991; IBGE, 2003) e de sua não associação direta à ideia de ilegalidade em certos casos, a questão tributária e o registro em carteira ainda predominam como critérios para definilos, sobretudo nas estatísticas oficiais. O circuito inferior, por sua vez, abriga diferentes combinações desses elementos ditos "formais" e "informais", ou seja, múltiplos arranjos relacionados às relações trabalhistas e ao pagamento de impostos (MONTENEGRO, 2006, p. 45). Destarte, os enfoques da informalidade não se confundem com a abordagem dos circuitos. Como coloca
Silveira (2004a, p. 68), "a escolha de um limite normativo que determina a formalidade e a informalidade das atividades [...] não nos parece um caminho de método fértil" para compreender o funcionamento das atividades no período atual, e tampouco sua a relação com o meio construído.

Ademais, o enfoque da informalidade tende a estabelecer dois universos teóricos para analisar o mesmo universo social (SLATER, 1982) e a não conferir historicidade à pobreza, uma vez que, muitas vezes divide o tecido social em uma suposta "sociedade moderna", a parcela formal, e em uma chamada "sociedade tradicional" ou "não capitalista" associada ao "setor informal". Parte-se do princípio de que os pobres não fazem uso das variáveis chave do período, como se esses não participassem do mesmo tempo histórico que os atores hegemônicos. Contudo, mesmo que os atores não hegemônicos não possuam o domínio das variáveis da época, ainda assim podem usá-las de outras formas.

\section{As relações do circuito inferior com as variáveis chave do período da globalização em São Paulo}

A expansão do circuito inferior em São Paulo no período atual está especialmente ligada à multiplicação de micronegócios. Durante a década de 1990, os micronegócios ampliaram sua participação em cerca de $2 \%$ no total de estabelecimentos do município; enquanto os estabelecimentos de médio porte reduziram sua participação em $1 \%$ e os grandes mantiveram sua participação praticamente inalterada (POCHMANN, 2002, p. 35). Embora cada unidade de produção, de comércio ou de serviços do circuito inferior possa oferecer 
apenas um pequeno número de ocupações, sua grande quantidade acaba por ter um efeito compensador sobre o mercado de trabalho. Dentre cerca de 200.000 estabelecimentos empregadores presentes no município de São Paulo, mais de $96 \%$ correspondiam a micro e pequenos estabelecimentos no ano de 2000 (POCHMANN, 2002, p. 36).

Esse efeito de compensação do circuito inferior também se manifesta na esfera do consumo. Pois embora as demandas individuais endereçadas a esse circuito sejam limitadas, o grande número de famílias que nele consome implica um efeito ampliado sobre sua parcela do mercado. A globalização das práticas de consumo da qual falavam Armstrong e McGee (1985) é, aliás, um dos dados chave que vem alterar o funcionamento do circuito inferior neste período. Ainda que a difusão do consumo e da informação date dos anos 1970, a força com que essas variáveis permeiam 0 conjunto do tecido social não apresenta paralelos frente ao impacto da publicidade e do crédito nos dias de hoje.

E é justamente a articulação entre uma propaganda onipresente e a expansão do crédito à população pobre que vem permitindo a concretização de um dos paradoxos que define o período atual, ou seja, o crescimento do consumo combinado ao aumento da pobreza (SILVEIRA, 2006, p. 165). A este quadro soma-se ainda um processo de endividamento brutal da população de baixa renda, aprofundando, por conseguinte, o caráter estrutural da pobreza urbana no país.

De todo modo, a sofisticação e a diversificação das formas de consumo do período vêm atingindo também os agentes do circuito inferior, uma vez que se amplia seu interesse em participar de formas de consumo próprias ao modo de vida moderno das classes mais abastadas. Uma grande parte da sociedade busca formas de não ser excluída desse consumo e, ao abrigo desse processo, a produção não hegemônica se fortalece, ou seja, o circuito inferior e o circuito superior marginal ganham um maior desenvolvimento nos dias de hoje (SILVEIRA, 2004a, p. 66).

Renova-se assim, ao mesmo passo, a "capacidade autoinflacionária" do circuito inferior, da qual falava McGee (1970). No campo de atividades que compõem o circuito inferior da cidade de São Paulo, a importância de suas atividades "típicas" conserva-se e expande-se no período atual, haja vista a expansão do pequeno comércio varejista de alimentos, da reparação de veículos, das lavanderias, dos salões de cabeleireiro, da fabricação de artefatos de couro, do comércio de vestuário, dos armarinhos, do comércio de artigos de perfumaria e de autopeças (SEBRAE, 2000); além dos diferentes tipos de trabalhos autônomos que compõem também esse circuito (prestadores de pequenos serviços, vendedores ambulantes, catadores etc.) e das diversas formas de trabalho doméstico.

Figura 1 - Salão de cabeleireiro na Rua do Rio Branco em Santo Amaro

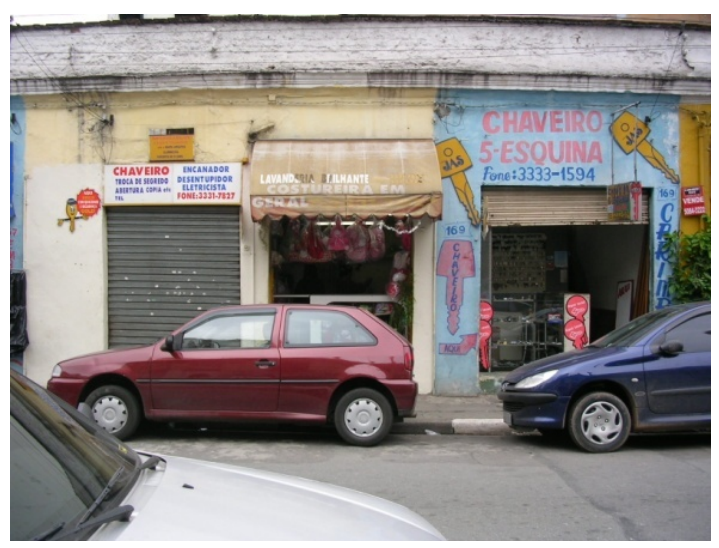

Foto: Lara Montenegro, 2005. 
No entanto, no período atual, expandem-se também as novas formas de manifestação desse circuito vinculadas especialmente à banalização do consumo de objetos ligados às variáveis chave do período entre as camadas pobres. A convergência da informática e das telecomunicações vem transformando as formas contemporâneas de produção e de comunicação, tanto no âmbito do circuito superior como no universo do circuito inferior a partir da transformação das "variáveis força" em "variáveis suporte". No momento de seu surgimento, as novas técnicas aparecem como uma "variável força", uma vez que se encontram inicialmente disponíveis apenas aos agentes hegemônicos; em um segundo momento, porém, as técnicas sofrem um processo de banalização e passam a compreender, por conseguinte, uma "variável suporte" para a participação na divisão do trabalho.

Figura 2 - Chaveiros e lavanderia e oficina de costura na Rua Couto Chagas no Bom Retiro

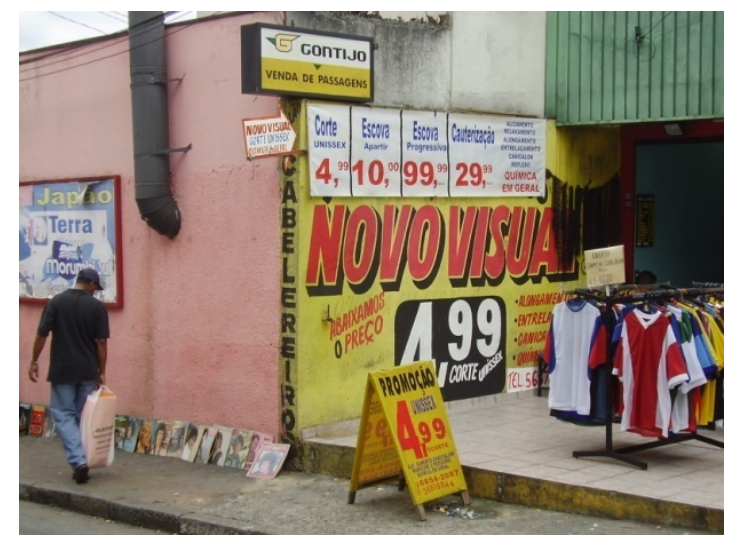

Foto: Felipe Caranassios, 2006.

Os aparelhos de telecomunicações como telefones celulares, os equipamentos de fotocópia, vídeo e fotografia, assim como os computadores, por exemplo, tornaram-se mais acessíveis aos agentes do circuito inferior e passaram a permear seu cotidiano tanto na esfera do consumo, como do trabalho. A banalização do acesso ao sistema técnico atual implica, assim, novas possibilidades de ação por parte destes atores, ainda que venha acompanhada de novos nexos de dependência e de subordinação. Este é certamente um dado novo do período.

Destarte, o circuito inferior continua a fazer uso de tecnologias obsoletas ou tradicionais; mas, por outro lado, no período atual, amplia-se a possibilidade do uso de técnicas relativamente modernas, embora os objetos que chegam a este circuito já se encontrem relativamente "superados" pela produção acelerada de novos objetos e pela obsolescência planejada do circuito superior. É o caso, por exemplo, das inúmeras "lojinhas" que passam a oferecer o serviço de fotocópia (xerox) ou de revelação instantânea de fotos (fotomáticas). Esses estabelecimentos, por seu capital reduzido e organização simples, não se equiparam às gráficas do circuito superior marginal, mas ainda assim têm suas formas e tempos de trabalho renovados. É o caso também das oficinas de conserto que ampliam seu leque de serviços a novos objetos como telefones celulares, impressoras, câmeras fotográficas, vídeos cassete, fax etc.

Embora esteja mais associada ao funcionamento do circuito superior marginal, a forte expansão do uso de microcomputadores pelas micro e pequenas empresas ao longo da década de 1990 também aparece como um dado sugestivo: em 1990 apenas $10 \%$ das micro e pequenas empresas paulistas utilizavam microcomputadores em suas atividades, em 2002 essa proporção passa para 47\% (SEBRAE, 2003).

Desse modo, tanto pela expansão dos novos produtos [...] transformados em instrumentos de trabalho das 
atividades não hegemônicas, como pela proliferação das atividades de reparo, os circuitos superior marginal e inferior participam, de forma crescente e às vezes contraditória, da produção da unicidade técnica (SILVEIRA, 2004b, p. 6).

Essa banalização crescente do uso de novas técnicas como instrumentos de trabalho em determinadas atividades do circuito inferior nos autorizaria a considerar que estas passam doravante a fazer parte de um circuito superior marginal? Acreditamos que não, visto que o grau de organização e capitalização destas atividades permanece bastante reduzido; ademais seu grau de modernização técnica não se equipara ao empregado pela porção marginal do circuito superior, cujos conteúdos técnico-informacionais se vinculam diretamente à racionalidade hegemônica.

Figura 3 - Stand de serviços e comércio de telefones celulares na Rua Santa Ifigênia

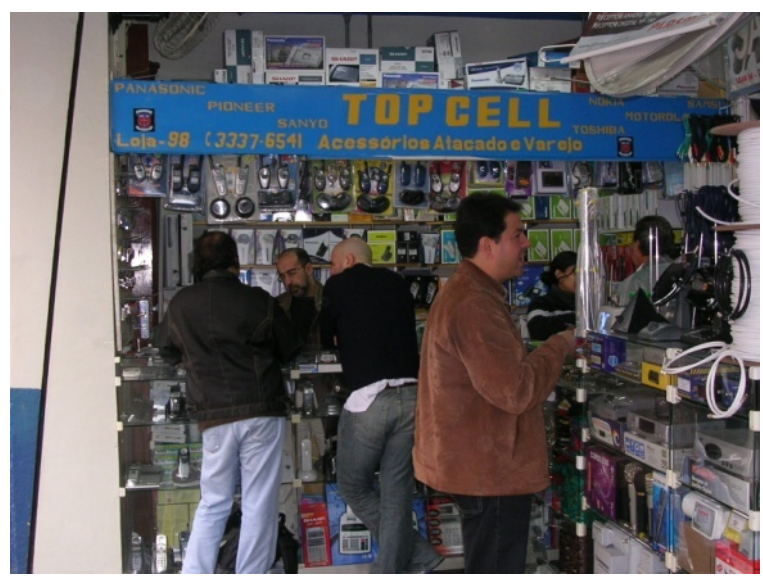

Foto: Felipe Caranassios, 2006.

O leque de produtos com o qual trabalha o circuito inferior no período atual amplia-se enormemente, haja vista, inclusive, a crescente participação de artigos não produzidos localmente. Este circuito trabalha hoje, em grande medida, com artigos que vêm de longe - em certos casos, inclusive com produtos importados - tanto no âmbito dos serviços como no comércio. Destarte, verifica-se que se em um momento anterior o circuito inferior tendia a trabalhar exclusivamente com artigos locais, hoje mesmo a cooperação do pequeno tende a se dar em circuitos mais amplos, por vezes internacionais, não se completando, assim, necessariamente na contiguidade.

Figura 4 - Oficina de conserto de televisões, computadores, videogames etc. na Rua Capitão Tiago Luz, em Santo Amaro

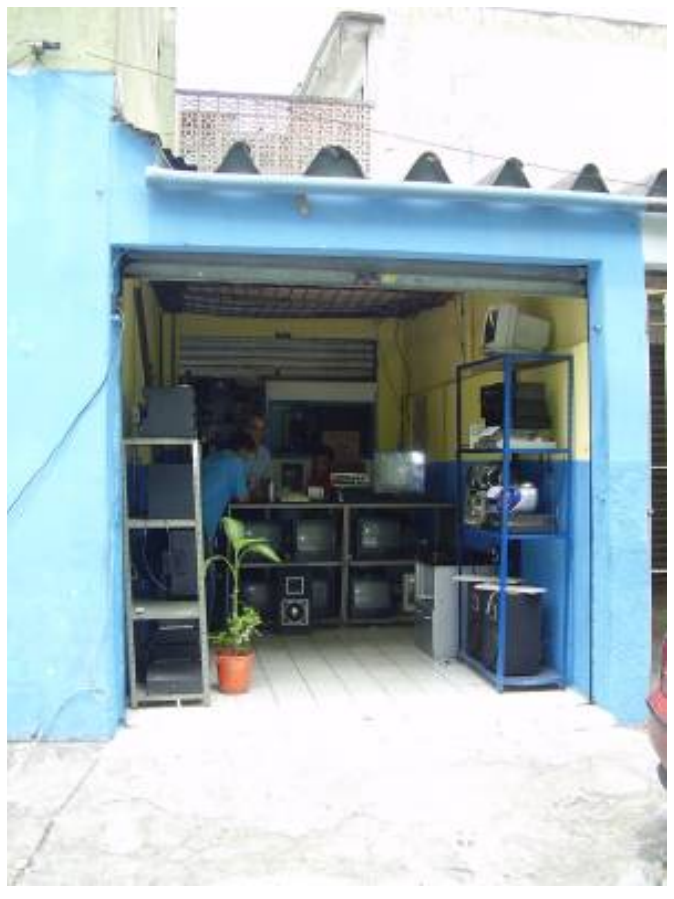

Foto: Lara Montenegro, 2005.

Outro fenômeno especialmente revelador da dinâmica do circuito inferior diz respeito aos gastos com a publicidade, que deixam de ser nulos nos dias de hoje. A publicidade passa a permear progressivamente este circuito, mesmo que sob formas extremamente simples como o "boca a boca", cartões de visita, faixas, banners, pequenos anúncios nas "Páginas Amarelas", cartazes, placas etc. Muitas vezes essas formas de propaganda são criadas pelos próprios pequenos estabelecimentos, em outros casos são produzidas em conjunto com gráficas, estreitando assim os laços de 
complementaridade entre os circuitos inferior e superior marginal.

Ademais, aquilo que aparece como propaganda para certos atores compreende trabalho para outros, ou seja, atualmente multiplicam-se as atividades de fabricação desses artigos, que são muitas vezes acompanhados do serviço de "colocação grátis" nas ruas. Acreditamos que é justamente nesse meio que reside um dos focos de criação de novas atividades que passam a compor o circuito inferior e o circuito superior marginal no período atual. ${ }^{2}$

A imitação - um dos fundamentos do funcionamento do circuito inferior (SANTOS, 1978) - também se renova no período atual, ampliando seus laços com a propaganda, com a moda, com as novas formas de produção (muitas vezes associadas à "pirataria" e, consequentemente, à marginalidade) e com a comercialização de um novo leque de produtos.

A variedade de formas de pagamento presentes no circuito inferior é outro elemento novo que o caracteriza atualmente e que expõe, por sua vez, sua relação com uma das variáveis centrais da globalização, ou seja, com as finanças. A banalização do acesso aos cheques e aos cartões de débito e crédito vem invadindo o circuito inferior, transformando sua relação com as finanças e com o crédito (MONTENEGRO, 2006). Ainda que continuem prevalecendo as pequenas operações em espécie, mesmo porque grande parte dos agentes do circuito inferior não possui conta bancária, algumas operações

\footnotetext{
2 Contudo, a Lei "Cidade Limpa", que proíbe a publicidade exterior e outdoors na cidade de São Paulo desde janeiro de 2007, limitou as atividades deste ramo em ambos os circuitos. O impacto desta medida é, no entanto, certamente maior entre os micro e pequenos negócios, para os quais o custo de realizar publicidade em outros meios de comunicação é, para a maioria, proibitivo.
}

passam a ser realizadas com cartões, especialmente com cartões de débito.

Por outro lado, o circuito superior também busca se aproveitar dessa banalização do crédito em meio às classes populares. Graças à presença massiva de grandes estabelecimentos comerciais nas diferentes centralidades da cidade e à oferta da possibilidade de pagamentos cada vez mais parcelados à população de baixa renda, o circuito superior vem invadindo progressivamente uma parcela do mercado, que tradicionalmente pertencia ao circuito inferior. Este é um dos aspectos reveladores do processo de financeirização da sociedade e do território pelo qual vem passando o país (SANTOS; SILVEIRA, 2001, p. 195).

Essas considerações sobre as dinâmicas que perpassam o circuito inferior no período atual nos revelam como os mais pobres utilizam, efetivamente, as variáveis da época de maneira ativa. A pobreza poderia ser olhada desta forma, evitamos assim o risco de olhar a pobreza como a-histórica, pois a pobreza atual é uma pobreza da globalização.

No Quadro 1, buscamos expressar a diversidade de atividades pertencentes ao circuito inferior na cidade de São Paulo no período atual. Vale destacar que com esse Quadro não pretendemos, de forma alguma, abarcar a totalidade de atividades pertencentes ao universo do circuito inferior de São Paulo, buscamos, todavia, ilustrar algumas de suas novas e "velhas" formas de trabalho que se fazem presentes atualmente na cidade. O Quadro procura mostrar, por outro lado, como a chamada "cidade global" brasileira abriga um grande leque de atividades não ligadas diretamente ao setor hegemônico da economia. 
Quadro 1 - Divisão do trabalho no circuito inferior da economia no município de São Paulo - 2006

\begin{tabular}{cl}
\hline & Comestíveis; bebidas; doçaria; farmácia; artigos de perfumaria; bijuterias; armarinho; \\
& tecidos e retalhos; confeç̃ões; sapataria; artigos domésticos; ferragens e materiais de \\
& construção; ferramentas; bombas/ motores/ borrachas/ plásticos/ acessórios para gás; \\
lojinha de 1 Real; quitandas; artigos nordestinos ("Casas do Norte"); artesanatos; banca \\
de jornal; papelaria; artigos de informática e telecomunicações de segunda mão; peças de \\
motocicletas, bicicletas e veículos; aparelhos eletroeletrônicos "no estado"; (*) máquinas de \\
costura de segunda mão; vendedores ambulantes; variados; outros.
\end{tabular}

Fonte: Montenegro (2006, p. 88).

(*) Várias microempresas localizadas no centro da cidade de São Paulo compram aparelhos usados ora para utilizá-los em seu próprio negócio ou para consertá-los e revendê-los; outras simplesmente revendem artigos quebrados ou com defeito - esses artigos são chamados "no estado".

Vale destacar que várias dessas atividades encontram-se, muitas vezes, combinadas entre si de diferentes formas. No centro da cidade, por exemplo, identificamos diversos estabelecimentos que oferecem uma variedade de serviços e de artigos não relacionados, conformando uma combinação que muitas vezes assume um caráter curioso. Mesmo em enclaves mais especializados na região da Praça da Sé, como, por exemplo, na Rua Barão de Paranapiacaba - conhecida como a "rua do ouro" - em um mesmo estabelecimento, são oferecidos os serviços mais diversos: gravação de nomes em bijuterias, conserto de relógios, troca de baterias, cópia de chaves, afiação de alicates de cutículas e de tesouras, confecção de carimbos. Em pequenas oficinas de conserto de máquinas de escrever e de calculadoras, são vendidos também cartuchos "recarregados" para impressoras etc. Muitas vezes chaveiros assumem a função de encanadores, pintores e eletricistas, além de oferecerem o serviço de fabricação de carimbos. Essa diversificação dos serviços e dos artigos oferecidos por um mesmo estabelecimento pode ser considerada como uma renovação das estratégias assumidas pelos agentes do circuito inferior no período atual (MONTENEGRO, 2006, p. 131).

Os supostos limites entre os "setores" de atividade, originados da proposta já clássica de Clark, $^{3}$ também se esvaem

3 Uma das classificações mais correntes das atividades produtivas em economia foi proposta por C. Clark. Segundo este autor, a economia de cada país é composta por três setores básicos: setor primário, setor secundário e setor terciário. Cada um desses setores engloba certas atividades que, por sua vez, também são compreendidas respectivamente como setores: atividades agropecuárias e extrativas; produção fabril, 
atualmente no circuito inferior, haja vista a realização de diversas atividades num mesmo pequeno estabelecimento. Ademais, vale lembrar que muitas das atividades elencadas podem pertencer, evidentemente, ao circuito superior marginal ou mesmo ao circuito superior, dependendo do grau de organização e capital envolvidos.

\section{Desvalorização do meio construído e circulação das massas}

Embora São Paulo seja uma grande metrópole corporativa, pode abrigar também os tempos mais lentos dos não hegemônicos, visto que nem todos os espaços são atingidos pela modernização. Como colocam Santos e Silveira (2001), ainda que a cidade busque adaptar-se às demandas da economia mais moderna, adequando o seu espaço construído às respectivas exigências, esse processo atinge apenas uma pequena parcela do território urbano, enquanto o resto da cidade mostra uma grande variação quanto à modernidade das infraestruturas disponíveis.

As áreas analisadas por nós na cidade de São Paulo - Largo Treze de Maio e distritos Sé, República, Santa Cecília e Bom Retiro - caracterizam-se pela presença em diferentes graus de um meio construído deteriorado, desvalorizado. E esta materialidade desvalorizada tem um efeito sobre a ação que nela se desenrola, ou seja, implica uma retroação, convidando à realização sobretudo de trabalhos não hegemônicos. Daí a ocorrência de uma série

construção civil e geração de energia; e serviços em geral como comércio, armazenagem, transportes, sistema bancário, saúde, educação, telecomunicações, energia elétrica, saneamento básico e administração pública (BEAUJEUGARNIER, 2006). de micro e pequenos estabelecimentos do circuito inferior nessas áreas. As formas utilizadas pelos atores não hegemônicos compreendem, assim, aquelas já existentes no meio construído urbano, resultantes de divisões territoriais do trabalho pretéritas, mas presentificadas pelas ações atuais que se dão sobre elas e a partir delas. O circuito superior em contrapartida, define-se justamente por sua capacidade de macroorganização do espaço (SANTOS, 1978), a qual se dá também na escala urbana através da renovação e da remodelação de determinadas parcelas da cidade.

Por outro lado, além da presença de um meio construído desvalorizado, o enorme fluxo cotidiano encontrado nas áreas estudadas da cidade de São Paulo constitui igualmente um fator central para a forte concentração de trabalhos não hegemônicos. Essas áreas abrigam uma intensa circulação de pessoas, constituindo ademais um ponto central de convergência dos meios de transporte da cidade e da Região Metropolitana de São Paulo. No centro, por exemplo, estima-se que a circulação realizada em transporte coletivo, em transporte individual e a pé envolva mais de 2 milhões de pessoas por $\mathrm{dia}^{4}$ (PMSP/PROCENTRO, 2001).

Esse enorme fluxo de pessoas
encontrado nesses lugares permite a
instalação de pequenas atividades do circuito
inferior que se sustentam sobretudo no
consumo das grandes massas. Assim,
podemos considerar que é a grande

\footnotetext{
4 Dentre as áreas que concentram o maior movimento de pedestres no centro, destacam-se os trajetos entre a Praça da Sé e o Parque Dom Pedro II, entre a Praça da República e a Praça da Sé e entre a região da Santa Ifigênia e a República.
} 
circulação cotidiana das massas, combinada à presença de um meio construído "desvalorizado", que autoriza a existência de uma série de pequenos estabelecimentos do circuito inferior.

Os conteúdos desses espaços são assim o insumo primordial de que dispõe o circuito inferior para perpetuar sua existência. Sistemas de ações e sistemas de objetos (SANTOS, 1996) assumem as mais variadas combinações nos lugares em questão, e são justamente certas combinações resultantes que permitem a sobrevivência de grande parte da população pobre da metrópole.

Figura 5 - Grande fluxo de pessoas na Rua Quinze de Novembro (Sé)

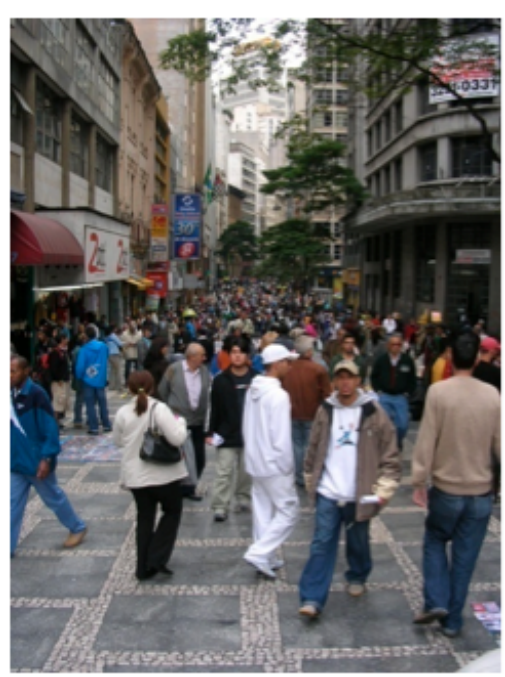

\section{Considerações finais}

Em um período em que a lógica de um mercado global se faz cada vez mais presente no território nacional, acreditamos que é ainda mais importante compreender o espaço como uma totalidade, isto é, atentar para todas as divisões do trabalho, para o conjunto dos aconteceres (SARTRE, 1990). Por isso, acreditamos que um olhar sobre o circuito inferior permitir-nos-ia entender como os atores não hegemônicos encontram um lugar na cidade em função do valor da atividade e da parcela do meio construído em que estão inseridos.

Por fim, tendo em vista a enorme dimensão assumida pelo circuito inferior na cidade de São Paulo, e também nas demais grandes cidades brasileiras, consideramos cada vez mais imprescindível, assim como queria Santos (1978, p. 23), que o circuito inferior seja levado em conta nas análises das realidades urbanas. Abre-se aí um caminho (SANTOS; SILVEIRA, 2001, p. 298) para fazer um contraponto a uma racionalidade, atualmente em prática, que não interessa à maior parte das empresas nem da população.

Foto: Felipe Caranassios (2006).

\section{Referências bibliográficas}

ARMSTRONG, W.; McGEE, T. Theatres of Accumulation: Studies in Asian and Latin American Urbanization. Cambridge: University Press, 1985.

BEAUJEU-GARNIER, J. Géographie urbaine. 4. ed. Paris: Armand Colin, 2006.

CACCIAMALI, M. C. As economias informal e submersa: conceitos e distribuição de renda. In: CAMARGO, J. M.; GIAMBIAGI, F. (Orgs.). Distribuição de renda no Brasil. São Paulo: Paz e Terra,1991. p. 121-143.
; SILVA, M. F. J. S. Emprego e seguridade social: mais uma década perdida no mercado de trabalho da América Latina. In: COGGIOLA, O. (Org.). América Latina: encruzilhadas da história contemporânea. São Paulo: ProlamUSP, 2003. p. 215-231.

INSTITUTO BRASILEIRO DE GEOGRAFIA E ESTATÍSTICA. Economia Informal Urbana, 2003.

Cadastro Central de Empresas 2002, 2006. 
LAUTIER, B. L'économie informelle dans le Tiers Monde. 2 ème. Paris: Découverte, 1994.

McGEE, T. Dualism in the Asian City: The Implications for City and Regional Planning. Hong Kong: University of Hong Kong, 1970.

MONTENEGRO, M. R. O circuito inferior da economia urbana na cidade de São Paulo no período da globalização. Dissertação (Mestrado em Geografia Humana) - Faculdade de Filosofia, Letras e Ciências Humanas da Universidade de São Paulo, São Paulo, 2006.

POCHMANN, M. (Org.). Desenvolvimento, trabalho e solidariedade: novos caminhos para a inclusão social. São Paulo: Fundação Perseu Abramo, 2002.

. Desenvolvimento, trabalho e renda no Brasil: avanços recentes no emprego e na distribuição dos rendimentos. São Paulo: Fundação Perseu Abramo, 2010.

PREFEITURA DO MUNICÍPIO DE SÃO PAULO. Procentro. Reconstruir o centro. Reconstruir a cidade e a cidadania. São Paulo, 2001.

ROCHA, S. Pobreza no Brasil: afinal, de que se trata? 3. ed. Rio de Janeiro: Editora Fundação Getúlio Vargas, 2003.

SANTOS, M.; SILVEIRA, M. L. O Brasil: território e sociedade no início do século XXI. Rio de Janeiro: Record, 2001.

A natureza do espaço: técnica e tempo, razão e emoção. São Paulo: Hucitec, 1996.

O espaço dividido: os dois circuitos da economia urbana dos países subdesenvolvidos. Tradução de Myrna T. Rego Viana. Rio de Janeiro: Francisco Alves, 1978.

SARTRE, J.-P. Critique de la raison dialectique. Paris: Gallimard, 1990.

SERVIÇO BRASILEIRO DE APOIO ÀS MICRO E PEQUENAS EMPRESAS. Boletim Estatístico de Micro e Pequenas Empresas. Sebrae, São Paulo, jul. 2005.

A informatização nas MPEs paulistas. Sebrae, São Paulo, ago. 2003.

Onde estão as MPEs paulistas. Pesquisas Econômicas, jul. 2000.

SILVEIRA, M. L. Metrópolis brasileñas: un análises de los circuitos de la economía urbana. Eure, v. XXXIII, n.100, dez. 2007, p. 149-164.

. Por que há tantas desigualdades sociais no Brasil? Um panorama da riqueza e da pobreza brasileira. In: ALBUQUERQUE, E. S. Que país é esse? Pensando o Brasil contemporâneo. São Paulo: Globo, 2006. p. 141-169.

. São Paulo: os dinamismos da pobreza. In: CARLOS, A. F. A. C.; OLIVEIRA, A. U. (Orgs.). Geografias de São Paulo: representação e crise da metrópole. São Paulo: Contexto, 2004a, p. 59-71.

- Globalización y circuitos de la economía urbana en ciudades brasileñas. Cuaderno del CENDES, ano 21 , v. 3, n.57, 2004b, p.1-21.

. Uma situação geográfica: do método à metodologia. Território, ano IV, $\mathrm{n}$. 6, jan./jun. 1999, p. 21-28.

SLATER, D. Capitalismo y desarrollo regional. Amsterdam: Cedla, 1982. 